\title{
Occurrence of Gastric Carcinoma in Patients Previously Affected with Esophageal Webs
}

\author{
FNU Raja ${ }^{2}$, Nathumal Maheshwari ${ }^{3}$, Mahnoor Ahsan ${ }^{2}$, Wish Hal Sundar ${ }^{2}$, Berkha Rani $^{2}$, Sana Sehar ${ }^{2}$, Nimra \\ Shahnawaz ${ }^{4}$, Muhammad Wasay Latif Shaikh ${ }^{5}$ and Sonia Shahid ${ }^{1}$
}

${ }^{1}$ Department of Medicine, Abbasi Shaheed Hospital, Pakistan

${ }^{2}$ Department of Medicine, JPMC, Pakistan

${ }^{3}$ Department of Pediatrics, SMBBMC, Pakistan

${ }^{4}$ Department Community Medicine, Karachi Medical \& Dental College, Pakistan

${ }^{5}$ Department of Oral \& Maxillofacial Surgery, Abbasi Shaheed Hospital, Pakistan

Submission: April 22, 2017; Published: April 28, 2017

"Corresponding author: Sonia Shahid, Department of Medicine, Abbasi Shaheed Hospital, Pakistan, Email: dr.sonyashahid@gmail.com

\begin{abstract}
The aim of this study was to determine the incidence of gastric cancer in patients who previously suffered from esophageal webs in Karachi, Pakistan. This prospective study was conducted from January 2015-February 2017 in tertiary care hospitals of Karachi, Pakistan. Sample size is 256. Patients of age 28-75 years, regardless of gender presenting with principal complain of dysphagia were recruited in this study. The dysphagia is usually painless and intermittent or progressive over years, limited to solids and sometimes associated with weight loss. Other associations were that the patients were weak and anemic. A complete medical history was taken and a thorough physical examination was carried out which was filled in the performa, by concerned doctors, designed by an application "FORMS". The most common etiological factors are iron deficiency, malnutrition, genetic predisposition or autoimmune processes. Esophageal webs can be detected by double barium swallow X-ray. Webs are also detectable by upper gastrointestinal endoscopy. Gastric cancer is the common cancer causing deaths worldwide. In this study the patients with esophageal webs were tested and treated. During their frequent follow up visits, they were also tested for possible gastric carcinoma by double-contrast barium meal to examine the stomach for gastric cancer and endoscopic ultrasound to check esophageal and gastric wall thickening for staging of cancer. Exact data about epidemiology is not available.
\end{abstract}

Keywords: Esophageal webs; Gastric carcinoma; Endoscopy; Barium swallow

\section{Objective}

To determine the incidence of gastric cancer in patients who previously suffered from esophageal webs coming to tertiary care hospitals of Karachi, Pakistan.

\section{Introduction}

Gastric cancer is the 2nd most common cause of death among all cancers in the world. The number of deaths due to gastric cancer is about 800,000 annually [1]. Gastric cancer is the second most common cancer worldwide and almost two-thirds of all cases occur in developing countries [2]. Gastric cancer is more common in men as compared to women and is 3rd most common cancer after colorectal and breast cancers in women [1]. An esophageal web is a thin $(2-3 \mathrm{~mm})$, eccentric, smooth extension of normal esophageal tissue consisting of mucosa and submucosa that can occur anywhere along the length of the esophagus but is typically located in the anterior postcricoid area of the proximal esophagus [3]. Esophageal webs arise in the upper esophagus and are thin layers of cells/folds that grow across the inside of the esophagus and block it either partially or completely [4]. In few studies gastrointestinal radiographic series demonstrated cervical esophageal webs and advanced gastric cancer [5]. It is well known that webs are associated with an increased incidence of hypopharyngeal or cervical esophageal cancer. However, it is even more unusual that this syndrome is combined with gastric cancer [6]. In this study, we determined the incidence of gastric cancer occurring in patients suffered initially from esophageal webs. The dysphagia is usually painless and intermittent or progressive over years, limited to solids and sometimes associated with weight loss. Symptoms resulting 
from anemia such as weakness, pallor, fatigue and tachycardia. Furthermore, it is characterized by glossitis, angular cheilitis and koilonychia (spoon-shaped finger nails). Enlargement of the spleen and thyroid can also be observed.

\section{Methodology}

This prospective study was conducted from January 2015-February 2017 in tertiary care hospitals of Karachi, Pakistan. Sample size is 256. Patients of age 28-75 years, regardless of gender presenting with principal complain of dysphagia were recruited in this study. Subjects that haven't completed at least 2 years follow up visit were excluded. A complete medical history was taken and a thorough physical examination was carried out which was filled in the performa, by concerned doctors, designed by an application "FORMS".

Since dysphagia is a main clinical feature, the differential diagnosis includes all other causes of dysphagia especially malignant tumors, benign strictures or esophageal rings. Also, diverticula, motility disorders such as achalasia, spastic motility disorders, scleroderma, diabetes mellitus, gastroesophageal reflux disease, and neuromuscular and skeletal muscle disorders.

Double-contrast barium meal is performed to examine the stomach for gastric cancer and endoscopic ultrasound was done to check esophageal and gastric wall thickening for staging of cancer. The staging was done according to following TNM classification:

Stage 0: This is also called carcinoma in situ. The cancer is found only on the surface of the epithelium. The cancer has not grown into any other layers of the stomach. This stage is considered an early cancer (Tis, N0, M0).

Stage IA: The cancer has grown into the inner layer of the wall of the stomach. It has not spread to any lymph nodes or other organs (T1, N0, M0).

Stage IB: Stomach cancer is called stage IB in either of these 2 conditions:

a. The cancer has grown into the inner layers of the wall of the stomach. It has spread to 1 to 2 lymph nodes but not elsewhere (T1, N1, M0).

b. The cancer has grown into the outer muscular layers of the wall of the stomach. It has not spread to the lymph nodes or other organs (T2, N0, M0).

Stage IIA: Stomach cancer is called stage IIA for any 1 of these conditions:

a. The cancer has grown into the inner layer of the wall of the stomach. It has spread to 3 to 6 lymph nodes but not elsewhere (T1, N2, M0).

b. The cancer has grown into the outer muscular layers of the wall of the stomach. It has spread to 1 to 2 lymph nodes but not elsewhere (T2, N1, M0). c. The cancer has grown through all the layers of the muscle into the connective tissue outside the stomach. It has not grown into the peritoneal lining or serosa or spread to any lymph nodes or surrounding organs (T3, N0, M0).

Stage IIB: Stomach cancer is called stage IIB for any 1 of these conditions:

a. The cancer has grown into the inner layers of the wall of the stomach. It has spread to 7 or more lymph nodes but not elsewhere. (T1, N3, M0).

b. The cancer has invaded the outer muscular layers of the wall of the stomach. It has spread to 3 to 6 lymph nodes but not elsewhere (T2, N2, M0).

c. The cancer has grown through all the layers of the muscle into the connective tissue outside the stomach but has not grown into the peritoneal lining or serosa. It has spread to 1 to 2 lymph nodes but not elsewhere (T3, N1, M0).

d. The cancer has grown through all the layers of the muscle into the connective tissue outside the stomach. It has grown into the peritoneal lining or serosa, but it has not spread to any lymph nodes or surrounding organs (T4a, N0, M0).

Stage IIIA: Stomach cancer is called stage IIIA for any 1 of these conditions:

a. The cancer has grown into the outer muscular layers of the stomach wall. It has spread to 7 or more lymph nodes but not to other organs (T2, N3, M0).

b. The cancer has grown through all the layers of the muscle into the connective tissue outside the stomach but has not grown into the peritoneal lining or serosa. It has spread to 3 to 6 lymph nodes but not to other organs (T3, N2, M0).

c. The cancer has grown through all the layers of the muscle into the connective tissue outside the stomach. It has grown into the peritoneal lining or serosa and has spread to 1 to 2 lymph nodes but not to other organs (T4a, N1, M0).

Stage IIIB: Stomach cancer is called stage IIIB for any of these conditions:

a. The cancer has grown through all the layers of the muscle into the connective tissue outside the stomach but has not grown into the peritoneal lining or serosa. It has spread to 7 or more lymph nodes but has not invaded any surrounding organs (T3, N3, M0).

b. The cancer has grown through all the layers of the muscle into the connective tissue outside the stomach and has grown into the peritoneal lining or serosa. It has spread to 3 to 6 lymph nodes but has not spread elsewhere (T4a, N2, M0). 
c. The cancer has grown through all the layers of the muscle into the connective tissue outside the stomach and has grown into nearby organs or structures. It may or may not have spread to 1 to 2 lymph nodes but not too distant parts of the body (T4b, N0 or N1, M0).

Stage IV: Stage IV stomach cancer describes a cancer of any size that has spread to distant parts of the body in addition to the area around the stomach (any T, any N, M1).

After gathering and classifying initial data, we used SPSS software version 16 for statistical analysis. T-test and ChiSquare tests were used. Continuous data were presented as mean $\pm S D$ and categorical data were presented as proportions. P-values less than 0.05 were considered statistically significant. According to the fact that all studies and therapies were based on patient's needs and we refused any unnecessary examinations and their private data will not be obtained by any factual or legal authorities, this research does not have any ethical problems.

\section{Results}

Total number of patients tested were 289 out of which 256 were recruited as they completed minimum 2 years of follow up visits. Male female ratio was 1: 10. Females were more affected with esophageal webs and so were more prone to develop gastric carcinoma. 256 patients had esophageal webs and were treated with esophagoscopy excision and dilation. On their every follow up visits, which was every 6 months, patients were examined and tested for gastric carcinoma by endoscopic ultrasound (Table 1).

Table 1: The results were summarized in following table.

\begin{tabular}{|c|c|c|c|c|c|}
\hline Stage & $\begin{array}{c}\text { After 6 } \\
\text { Months } \\
\text { Follow } \\
\text { Up }\end{array}$ & $\begin{array}{c}\text { After } \\
\text { 1 Year } \\
\text { Follow } \\
\text { Up }\end{array}$ & $\begin{array}{c}\text { After 18 } \\
\text { Months } \\
\text { Follow } \\
\text { Up }\end{array}$ & $\begin{array}{c}\text { After 2 } \\
\text { Years } \\
\text { Follow } \\
\text { Up }\end{array}$ & $\begin{array}{c}\text { More } \\
\text { Than 2 } \\
\text { Years } \\
\text { Follow } \\
\text { Up }\end{array}$ \\
\hline No & 256 & 238 & 221 & 173 & 109 \\
\hline Stage 0 & - & 18 & 22 & 34 & 55 \\
\hline Stage IA & - & - & 9 & 20 & 37 \\
\hline Stage IB & - & - & 3 & 11 & 22 \\
\hline Stage IIA & - & - & 1 & 9 & 14 \\
\hline Stage IIB & - & - & - & 4 & 7 \\
\hline Stage IIIA & - & - & - & 4 & 5 \\
\hline Stage IIIB & - & - & - & 1 & 4 \\
\hline Stage IV & - & - & - & - & 3 \\
\hline
\end{tabular}

Among 256 patients, 147 patients had gastric carcinoma after esophageal webs whereas 109 patients remain healthy after getting treatment of esophageal webs.

\section{Discussion}

The relation between esophageal webs and gastric carcinoma is very critical and unexpected. According to collected data, most of the patients were middle aged women. Surgery to remove the stomach (gastrectomy) is the only treatment that can cure or somewhat make the condition better. Radiation therapy and chemotherapy may help. For many patients, chemotherapy and radiation therapy after surgery may improve the chance of a cure but prognosis is not very good.

A surveillance upper gastrointestinal endoscopy is recommended every year to prevent the recurrence of esophageal webs and gastric carcinoma [7]. The future perspective is that the number of global cancer deaths is projected to increase by $45 \%$ from 2008 to 2030 (from 7.9 million to 11.5 million deaths), influenced in part by an increasing and aging global population. The estimated rise is expected slight declines in death rates for some cancers in high resource countries. New cases of cancer in the same period are estimated to rise from 11.3 million in 2008 to 15.5 million in 2030 as per WHO statistics [8].

\section{Acknowledgement}

This article is intended for research and educational purpose only. It did not receive any specific grant from funding agencies in the public, commercial, or not-for-profit sectors, it is totally author's funded study.

\section{References}

1. Daniyal M, Ahmad S, Ahmad M, et al. (2015) Risk Factors and Epidemiology of Gastric Cancer in Pakistan. Asian Pac J Cancer Prev 16(12): 4821-4824.

2. Zali H, Rezaei-Tavirani M, Azodi M (2011) Gastric cancer: prevention, risk factors and treatment. Gastroenterol Hepatol Bed Bench Autumn 4(4): 175-185.

3. http://emedicine.medscape.com/article/186561overview?pa $=\mathrm{KQ} \% 2 \mathrm{BoDurjugvy} 0 \mathrm{JAamCn} \% 2 \mathrm{FUYjlegv} 4 \mathrm{glI3zJ} 64 \% 2 \mathrm{~B} 0 \mathrm{IB}-$ 5 g 0 W LYO 1 W m 61 y C G T t Z 9 R 3 v OXX 8 M w C 0 E E Cw z p 432Skuf9qw\%3D\%3D

4. https://www.drugs.com/health-guide/esophageal-rings-and-webs. html

5. Kitabayashi K, Akiyama T, Tomita F (1998) Gastric cancer occurring in a patient with Plummer-Vinson syndrome: Report of a case. Surg Today 28(10): 1051-1055.

6. Larsson LG, Sandström A, Westling P (1975) Relationship of Plummer-Vinson disease to cancer of the upper alimentary tract in Sweden. Cancer Res 35(11 pt. 2): 3308-3316.

7. Hoffmann RM, Jaffe PE (1995) Plummer-Vinson syndrome. A case report and literature review. Arch Intern Med 155(18): 2008-111.

8. Zali K, Rezaei-Tavirani M, Azodi M (2011) Gastric cancer: prevention, risk factors and treatment. Gastroenterol Hepatol Bed Bench 4(4): 175-185. 
This work is licensed under Creative Commons Attribution 4.0 License

DOI: $10.19080 /$ ARGH.2017.04.555654

\section{Your next submission with Juniper Publishers} will reach you the below assets

- Quality Editorial service

- Swift Peer Review

- Reprints availability

- E-prints Service

- Manuscript Podcast for convenient understanding

- Global attainment for your research

- Manuscript accessibility in different formats ( Pdf, E-pub, Full Text, Audio)

- Unceasing customer service

Track the below URL for one-step submission https://juniperpublishers.com/online-submission.php 